Discussion Paper No. 05-04

\title{
Unemployment, Labor Market Transitions, and Residual Wage Dispersion
}

Bernd Fitzenberger and Alfred Garloff

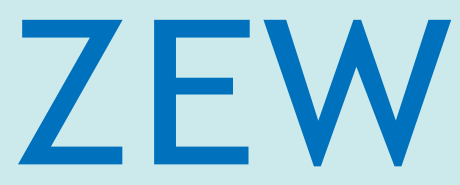

Zentrum für Europäische Wirtschaftsforschung $\mathrm{GmbH}$

Centre for European

Economic Research 
Discussion Paper No. 05-04

\title{
Unemployment, Labor Market Transitions, and Residual Wage Dispersion
}

\author{
Bernd Fitzenberger and Alfred Garloff
}

Download this ZEW Discussion Paper from our ftp server:

ftp://ftp.zew.de/pub/zew-docs/dp/dp0504.pdf

Die Discussion Papers dienen einer möglichst schnellen Verbreitung von neueren Forschungsarbeiten des ZEW. Die Beiträge liegen in alleiniger Verantwortung der Autoren und stellen nicht notwendigerweise die Meinung des ZEW dar.

Discussion Papers are intended to make results of ZEW research promptly available to other economists in order to encourage discussion and suggestions for revisions. The authors are solely responsible for the contents which do not necessarily represent the opinion of the ZEW. 


\section{Nontechnical summary}

It is commonplace in the debate on Germany's labor market problems to argue that high unemployment and low wage dispersion are related. The hypothesis that low wage dispersion is the reason for high unemployment is motivated by the different trends in unemployment and wage inequality when comparing the U.S. and continental Europe. This notion was put into a nutshell by Krugman (1994) who argues ,....that growing U.S. inequality and growing European Unemployment are different sides of the same coin". Accordingly, increased relative wages for the high-skilled and decreased relative wages for the low-skilled in the U.S. are the results of (accelerated) skill-biased technical change, (increasing) globalization or organizational changes. If continental Europe is equally affected by these trends, one would expect to observe similar changes in the wage structure. Since this is not the case, the economic and political debate blames institutions in Europe, such as generous social benefits and strong labor unions, to cause an inflexibility of the wage structure. This view, however, has not remained unchallenged. Opponents of this view emphasize that employment trends are too similar across countries for different skill groups, since the former approach implies that mainly the group of low-skilled should be affected by reverse employment trends.

Making the connection between wages or the wage structure on the one hand and the employment structure on the other hand operational for empirical testing is complicated because of the considerable heterogeneity in the input factor labor. Nevertheless, several attempts have been made to examine this relationship empirically. In general, these studies interpret differences in unemployment rates between a small number of (skill) groups as indicator for wage compression across these groups. Most of these studies find evidence for wage compression to cause the high European unemployment. An important theoretical distinction in the literature is made between residual wage dispersion for individuals with comparable attributes and wage dispersion between groups with different attributes. So far, empirical studies have focused on the relationship between employment and wages regarding wage differentials between groups, thus ignoring residual wage dispersion. Our study tries to fill this research gap by analyzing the relationship between unemployment, labor market transitions and residual wage dispersion for the case of West Germany.

This paper is the first attempt to discriminate empirically between the impact of two important labor market theories for labor market dynamics, employment, and wage dispersion. In the conventional neoclassical point of view, which we call the heterogeneity hypothesis, wages are determined by the marginal product of workers. Accordingly, residual (unexplained) wage dispersion corresponds to residual (unobserved) heterogeneity. Taking into account the German institutional context leads us to consider the effects of union minimum wages. We argue that they result in a decline of residual wage dispersion and higher unemployment, thereby supporting Krugman's view. Correspondingly, low wage dispersion implies high entry rates to unemployment and low exit rates out of unemployment. A competing view, the frictional hypothesis, explains 
wage dispersion as the result of firms wage policies. The capacity to design independent wage policies stems from the monopsony power that firms possess in markets that are characterized by search frictions. An increase in the monopsony power of firms through increasing search frictions causes both higher wage dispersion and higher unemployment, thereby contradicting Krugman's view. For the labor market dynamics this implies that the job finding rates are low and that the job destruction rate is high. The empirical analysis attempts to discriminate between the two hypotheses for West Germany analyzing the relationship between residual wage dispersion and both the level of unemployment as well as the transition rates between different labor market states. Using panel methods we allow for correlated unobserved heterogeneity and an arbitrary structure of the covariance matrix. The findings are not completely consistent with either theory. Taken together, however, the frictional hypothesis seems to perform better than the heterogeneity hypothesis. Contradicting the conventional wisdom, one robust result is that unemployment by cells is not negatively correlated with the within-cell wage dispersion. 


\title{
Unemployment, Labor Market Transitions, and Residual Wage Dispersion
}

\author{
Bernd Fitzenberger (Goethe-University Frankfurt, IFS, IZA, ZEW) ${ }^{+}$ \\ and \\ Alfred Garloff (ZEW)*
}

January 2005

\begin{abstract}
It is commonplace in the debate on Germany's labor market problems to argue that high unemployment and low wage dispersion are related. This paper analyses the relationship between unemployment and residual wage dispersion for individuals with comparable attributes. In the conventional neoclassical point of view, wages are determined by the marginal product of the workers. Accordingly, increases in union minimum wages result in a decline of residual wage dispersion and higher unemployment. A competing view regards wage dispersion as the outcome of search frictions and the associated monopsony power of the firms. Accordingly, an increase in search frictions causes both higher unemployment and higher wage dispersion. The empirical analysis attempts to discriminate between the two hypotheses for West Germany analyzing the relationship between wage dispersion and both the level of unemployment as well as the transition rates between different labor market states. The findings are not completely consistent with either theory. However, as predicted by search theory, one robust result is that unemployment by cells is not negatively correlated with the within-cell wage dispersion.
\end{abstract}

Keywords: search friction, labor demand, labor market transitions, wages JEL-Classification: E24, J21, J31, J64

\footnotetext{
This work is part of the research project "Bildung und Verwertung von differenziertem Humankapital" as a part of the research group "Heterogene Arbeit: Positive und Normative Aspekte der Qualifikationsstruktur". Financial Support by the German Science Foundation (DFG) is gratefully acknowledged. We thank participants of seminars in Lisbon, Madrid, Frankfurt, Mons and Mannheim with special thanks to Martin Biewen, Bernhard Boockmann, Karsten Kohn, Anja Kuckulenz, François Laisney, Charlotte Lauer, Costas Meghir, Lars Nesheim, Friedhelm Pfeiffer, Jörn-Steffen Pischke, Jean-Marc Robin, and Ralf Wilke for helpful comments and Michaela Deppe and Tobias Tönnesmann for excellent research assistance. The usual disclaimer applies.

+ Corresponding author: Bernd Fitzenberger, Department of Economics, Goethe-University Frankfurt, PO Box 1119 32, D-60054 Frankfurt am Main, Germany, E-mail: fitzenberger@wiwi.unifrankfurt.de.

* Alfred Garloff, Centre for European Economic Research (ZEW), PO Box 1034 43, D-68034 Mannheim, Germany, E-mail: garloff@zew.de.
} 


\section{Contents}

\begin{tabular}{lll}
\hline & Introduction & 1
\end{tabular}

\begin{tabular}{|lll}
2 & Theoretical Discussion & 3
\end{tabular}

2.1 Marginal Productivity Theory . . . . . . . . . . . . . . . . . . 4

2.2 Search Framework $\ldots \ldots \ldots$

3 Testing the Heterogeneity Hypothesis and the Frictional Hypothesis 11

3.1 Data . . . . . . . . . . . . . . . . . . . . 12

3.2 Descriptive Evidence $\ldots \ldots \ldots$

3.3 The Relationship between Transitions and Wages . . . . . . . . . . . . 17

\begin{tabular}{lll}
\hline 4 & Conclusions & 25
\end{tabular}

\begin{tabular}{lr}
\hline Appendix & 26
\end{tabular}

\begin{tabular}{lr}
\hline References & 29
\end{tabular} 


\section{Introduction}

Wages and the wage formation process are crucial for understanding the labor market and, in particular, the causes for the high unemployment in Germany. Labor demand reacts on wages sensibly measured in efficiency units. Classical economic theory often concentrates on the role of human capital, may it be general or specific, where the explanation of wages or wage growth is concerned. A big part of the empirical literature on wages concentrates on estimating Mincer Equations, thereby estimating returns to schooling and returns to professional experience. If individuals are indeed paid according to their marginal productivity, which is itself determined by the human capital endowment, then we expect that wage differentials stem only from differences in marginal productivity. Wages, however, differ between observationally equivalent workers. We call these differences residual wage dispersion and postulate that, if the human capital approach to wages is correct, the residual wage dispersion is explained by unobserved productivity differences. From an empirical point of view, one can control for a part of this residual variation if allowing for effects that come from specific firms ("high wage firms", see Abowd, Kramarz, and Margolis (1999)) or from specific industries. This observation challenges the classical human capital model which assumes perfect competition and which allows neither for firm-specific differences nor for industry-specific effects, except for the case that the unobserved productivity differences are correlated with firms or specific industries 11 Even allowing for industryspecific effects, the relatively poor performance of this model in explaining the variance of observed cross-sectional wages casts doubt on this theoretical framework. Even studies that control for a wide variety of explanatory variables beyond economic theory are often not able to explain more than $50 \%$ of the observed variance in wages (see among others Kuckulenz and Zwick (2003) as a recent study for Germany).

Search theory offers both an interesting alternative and complement to marginal productivity theory and human capital theory by focusing on search frictions as an explanation for wage differences among workers with identical marginal productivity. The basic idea is that under imperfect information, there is a match-specific rent because of opportunity costs of waiting for a better match. Then, the wage is not unique and does not necessarily correspond to the marginal product. Equally productive workers face different possible wages (or even a whole distribution) for which they could work. Under this perspective, the reason why firms pay different wages is that search frictions lend them monopsony power, which they can exploit to different degrees. On the one

\footnotetext{
${ }^{1}$ In the classical framework, high wage firms might have attracted high ability individuals. However, empirical evidence even supports the contrary. Abowd, Creezy, and Kramarz (2002) and Gruetter and Lalive (2004) find that person and firm effects are negatively correlated.
} 
hand, there might be high-wage firms that have to pay high wages in order to assure their high employment. On the other hand, there might be low-wage firms that employ only a small number of employees since they lose them at a fast rate to their better paying competitors. Wage decompositions that try to identify the effect of search frictions on the basis of search equilibrium models attribute a considerable amount of the wage variation to search frictions. ${ }^{2}$ Search equilibrium models themselves predict a close association between wages and labor market transitions. When implementing these models empirically, a lot of identifying and non-testable assumptions typically have to be imposed on the data (see e.g. Bontemps, Robin, and Van den Berg (2000), Van den Berg and Ridder (1993), or Rosholm and Svarer (2004) for the implementation of a search-matching model).

We follow a slightly different approach here. Starting with the Krugman (1994) hypothesis that the relatively small wage dispersion in Europe might be the reason for the high unemployment in European countries, we distinguish two types of wage dispersion. We distinguish conceptually wage dispersion between individuals of different marginal productivity ("between wage dispersion") and wage dispersion within a group of individuals with identical marginal productivity ("within wage dispersion") because, from a theoretical point of view, the reasons for these might be different. Since in the empirical application, we are not able to control perfectly for differences in marginal productivity, we refer to residual wage dispersion as the empirical counterpart of within wage dispersion. Regarding between wage dispersion, there is empirical evidence for Germany that wages are compressed across groups of different human capital endowments (as a proxy for marginal productivity) and that this compression has led to high unemployment, especially for the group of low-skilled (see among others Fitzenberger and Kohn (2004)). Although this view that the compressed wage structure in European countries has led to high unemployment seems to be the conventional wisdom among economists, it has not remained unchallenged since the trends in the employment to population ratios across skill groups and countries are quite similar (see e.g. Krueger and Pischke (1998) and Card, Kramarz, and Lemieux (1999)).

Regarding within wage dispersion, the relationship with employment has rarely been investigated. This paper attempts to fill this research gap. Starting from search theory on the one hand and from classical theory on the other hand, we discuss competing hypotheses with respect to the relationship between labor market transitions and within wage dispersion. On the one hand, classical theory based on marginal productivity determining factor prices predicts that wage dispersion is determined by individual

\footnotetext{
${ }^{2}$ By search equilibrium models, we refer to a class of models based on search frictions which explicitly model the decision problem of both sides of the labor market and which imply an endogenous wage distribution.
} 
heterogeneity. So, if the within wage dispersion is small for institutional reasons (such as union bargaining power or high levels of public assistance), we expect comparably high unemployment rates. On the other hand, search theory predicts an opposite relationship between the two variables. Here, a small amount of search frictions is responsible for the low within wage dispersion. At the same time, low search frictions lead to a low unemployment rate.

To our knowledge, this paper is the first attempt in the literature to test between the different empirical implications of the two theoretical approaches $3^{3}$ We use a large administrative labor market data set for West Germany, the IAB-Beschäfigtenstichprobe (IABS), which covers the time period 1975 to 1997 and which contains precise information on wages and the timing of changes in employment status. We define cells in which individuals are homogenous with respect to age and education. Using this dataset, we first describe labor market transitions and wage changes following a job-to-job change, one of the key determinants in job search models. Then, we look at the wage structure and ask for the determinants of changes in the relative position in the wage distribution. Finally, we estimate how the rates at which labor market transitions take place and unemployment depend on the dispersion of the wage distribution and vice versa. Our conclusions about the influence of the transition rates on our dispersion measure and vice versa with respect to our hypotheses are rather mixed. However, one remarkable and stable result in favor of a frictional view of the labor market persists: we find that there is no negative relationship between the unemployment rate and wage dispersion. This result, which is surprising for Germany, contradicts the hypothesis that labor unions might compress wages within each cell (see Krueger and Pischke (1998)), thereby causing high unemployment.

The structure of the paper is as follows: First, we present the two competing theories, deducing hypotheses for empirical testing. Then, we present some descriptive evidence for transitions and the wage structure. As the main part of the empirical analysis, we test both theories more strictly. Finally, we conclude and the appendix provides the precise definition of variables used in the empirical analysis.

\section{Theoretical Discussion}

From the neoclassical point of view, wages are equal to the marginal productivity of a person which is determined by the human capital endowment of a person after controlling for differences in physical capital usage. In a competitive market, there

\footnotetext{
${ }^{3}$ This idea has also been used by our associated paper Fitzenberger, Garloff, and Kohn (2003), however, the scope of the analysis in that paper is much more limited compared to this paper.
} 
is no room for firm (size) wage differentials, nor is there room for unemployment. Responding to the challenge of explaining these empirical regularities of labor markets, variations of the classical approach have been developed. On the other hand, competing theories based on search theory lead to different conclusions. This section, discusses both theoretical approaches and derives competing implications for empirical testing, even though the predictions of both theories do not differ in many respects.

\subsection{Marginal Productivity Theory}

Classical theory often assumes that markets are in a competitive equilibrium. If there is indeed a competitive market for labor, the same efficiency unit of labor will be paid the same wage, irrespectively of where it is employed. In addition, there should exist no firm wage differentials since relatively unproductive firms will be driven out of the market. If these assumptions are correct, human capital theory (Becker (1964)) predicts that individuals will acquire an optimal amount of human capital by choosing the optimal amount of years of schooling. The optimal level of investment might be different across individuals if they have different learning efficiencies $4^{4}$ Furthermore, they will acquire general and specific human capital while working.

As argued above, however, the wage seems not to be completely determined by the human capital endowment of an individual. From the econometric point of view, there are other factors that contribute significantly to the explanation of an individual's wage. As mentioned above, we distinguish conceptually two types of wage dispersion. The empirical counterpart of the conceptual distinction are the wage dispersion between groups characterized by their human capital endowments (as measured by potential experience and education) and the residual wage dispersion within a group of - with respect to the Mincerian approach $5^{5}$ - equivalent individuals. If we try to explain the wage dispersion between groups, it is determined by the human capital endowment of this group of individuals. From this theoretical point of view, however, it seems difficult to explain wage dispersion among identical individuals. Strictly speaking, if two individuals have the same marginal productivity they should earn exactly the same wage and therefore, there is no within wage dispersion. The first exception might be related to firms employing different capital stocks or technologies. But this situation should not persist in competitive markets. The second exception arises if there is specific human capital. In this case, even if we are able to measure true human

\footnotetext{
${ }^{4} \mathrm{~A}$ formal derivation of this idea in the perfect competition setting that implies differences in human capital investments across individuals can be found e.g. in Cahuc and Zylberberg (2001), p.177ff.

${ }^{5}$ That is, we control for educational attainment and (potential) experience.
} 
capital $!^{6}$ endowment, the wage is not uniquely determined by the amount of human capital but can be negotiated between the firm and the worker, since - by definition the specific capital is of no use in other firms (see, e.g. Franz (2003), pp. 306ff., Cahuc and Zylberberg (2001), pp. 193ff.).7

Further sources of residual wage dispersion are due to measurement issues. First, we might not be able to measure human capital correctly because of data restrictions. Second, there might be unmeasurable qualities of individuals, like ability, that affect marginal productivity. ${ }^{8}$

When applying this theory to the German labor market, an important question is whether this theory is able to explain the high unemployment level in Germany. At first sight unemployment is difficult to explain in a perfect competition setting. However, accounting for the fact that, especially in Germany, labor unions have a significant influence on the wage formation process, wages might differ from their equilibrium value. More precisely, unions in Germany bargain with employers on a schedule of minimum wages for different types of jobs. The so-called "to-the-worker's-advantage" principle ("Günstigkeitsprinzip") allows firms to pay more but not less than the wage that is agreed upon by unions and the employers' association. Suppose that, indeed, labor unions and employer associations agree upon a minimum wage. If this minimum wage is binding in the sense that there are individuals who have gained less, there will be at least a part of these individuals who will not be employed any more. Separate union contracts exist for different professional groups and different industries. We expect that there is in general more than one binding minimum wage for individuals with identical observed human capital endowment since they might be employed in different industries. However, a smaller wage dispersion across individuals with identical observed human capital endowment can, ceteris paribus, be interpreted as originating from higher minimum wages set by labor unions 9 In the empirical part, we will apply

\footnotetext{
${ }^{6}$ We define human capital as all individual traits which influence the (marginal) productivity of an individual.

${ }^{7}$ The residual wage dispersion can also be the result of compensating wage differentials among observationally equivalent workers. For the purpose of this paper, they can be treated in the same way as differences in marginal productivity.

${ }^{8}$ Measurement error is only important for the empirical concept of residual wage dispersion, since it is not possible to control for all productivity relevant characteristics. One should always be careful, whether one thinks of determinants of within wage dispersion for individuals that are indeed equally productive or whether one thinks of determinants of residual wage dispersion between individuals where some attributes have been controlled for, but where marginal productivity might still vary.

${ }^{9}$ Obviously, this raises the question why labor unions set wages too high. One possible reason is that at least some of the low wage employees gain from the minimum wage if they are still employed and paid a higher wage rate. In this case, we can give the behavior of the unions an Insider-Outsider interpretation. Furthermore, there might be other reasons that explain a compressed wage structure in a marginal productivity framework, as for example the wage rigidity literature (see e.g. Pfeiffer (2003)).
} 
this interpretation to the connection between wage dispersion, minimum wages and unemployment.

Empirical testing should also consider the dynamics of the labor market as reflected by transition rates between different labor market states. The classical framework is a static one, i.e. a long-term equilibrium framework. However, since markets need time to adapt to equilibrium values, it is realistic to assume that unemployment does not react immediately to a change of the binding minimum wage. This is implied by the dynamic theory of labor demand with adjustment costs (Hamermesh (1993)). Moreover, we expect that, as a reaction to an increase of a binding minimum wage, more labor contracts will end. That is, we observe an increasing rate of transitions from employment to unemployment (an increasing job destruction rate) since some of the matches which have been profitable previously become unprofitable. If this change is unanticipated, however, this adjustment might take time and firing rates do not increase immediately. Conversely, we observe fewer transitions from unemployment to employment since the potential match between employee and employer will become less profitable. Here even if the change in wage dispersion is unanticipated, we expect that the hiring rate reacts immediately, since jobs are only filled if they are profitable.

Another rate that reflects labor market dynamics and that is of particular importance for the subsequent search theoretic discussion is the transition rate from job-to-job. If we allow for a slow adoption of the wage to marginal product remuneration after, say, a technology shock, it is not clear how this relates to the wage distribution and to the rate at which job-to-job changes take place. From this point of view, we therefore do not have a clear prediction for the relationship between residual wage dispersion and the rate at which job-to-job changes take place.

We summarize the empirical implications by the following proposition.

Proposition 1 (Heterogeneity Hypothesis): Consider a cell of observationally equivalent workers. If the residual wage dispersion decreases, then the cell-specific unemployment rate increases, the transition rate from unemployment to employment declines, and the transition rate from employment to unemployment increases, possibly with a lag. There is no clear relationship between job-to-job changes and wage dispersion. Transition rates do not affect future wage dispersion.

\subsection{Search Framework}

The discussion so far has assumed that individuals with an identical observed human capital endowment are still heterogeneous with respect to their marginal productivity 
and that they are paid according to it. This section is based on a different view of the labor market. After having controlled for the educational level and for experience, assume that indeed individuals are identical with respect to their marginal productivity or, at least, that the employer cannot observe the differences. In addition, we drop the assumption that the individual is perfectly informed about his/her market wage. There is imperfect information ${ }^{10}$ for both sides of the labor market, since there are costs for the employers to search for new employees and for the employees to find employers. Let these costs only consist in the opportunity cost of the time it takes to find a match. Then, given that an employer and an employee have come together, there is a rent to be divided between them, since it is costly for both not to agree upon a contract (a match-specific rent). For the employer the fallback option consists in a vacancy that does not produce anything until the next meeting with an employee takes place (zero profit), while, as demonstrated in the seminal paper by Burdett and Mortensen (1998), in equilibrium every match generates positive profits. For the employee, the opportunity cost consists of the difference between the wage and the reservation wage which reflects his optimal decision when to accept a wage offer.

Given the existence of match-specific rents, the wage for identical individuals is not uniquely defined. From economic theory, it is not clear how this rent is shared between the parties; there is a whole range of possible mechanisms which define the rent sharing, depending on what one assumes to be a plausible assumption. In this paper, we assume that the wage is set by the employer, as a "take it or leave it" offer for the employee 11 In equilibrium it pays for the ex ante identical firms to choose different strategies and to offer different wages. The reason for this is that in equilibrium large and small firms coexist. Large firms will pay high wages in order to attract many individuals working at competing firms and to lose only little staff to competitors. The high employment comes at the cost of small profits per employee. Firms that pay low wages, on the contrary, will have high profits per employee but only a small staff, since they lose their employees at a high rate to their better paying large competitors. This implies that for the employee it is not clear, ex ante, at which wage rate he will initially be employed. In addition, while being employed he moves to better paying jobs over time since he receives offers from other firms. For this setup, Burdett and Mortensen (1998) show that the individual faces a continuous distribution of wages at which he could be employed.

\footnotetext{
${ }^{10}$ This is most probably a reasonable assumption since most people might know more or less but not exactly what they can earn.

${ }^{11}$ Other mechanisms are explored in Mortensen and Pissarides (1999). Although this mechanism might lead to situations where possibly profitable matches do not take place, this is "consistent with how many labor economists view the wage setting process" (ibid., p. 2607).
} 
The decision of an individual searching for a job is then whether to accept a certain wage offer or to wait for the next one. To do this he compares the value of accepting the job with the value of remaining unemployed (in the sense of expected income). If indeed, as suggested here, the equilibrium result is wage dispersion among identical individuals, the residual wage dispersion we observe in the data does not necessarily reflect differences in productivity but instead it is a result of search frictions ${ }^{12}$ But search frictions themselves also affect the equilibrium unemployment rate, thus predicting that higher search frictions lead to higher wage dispersion and to higher (involuntary) unemployment. Below, we will give a formal derivation of these arguments.

Consider a labor market where infinitely many individuals (with measure $N$ ) are either employed or unemployed. If employed, they produce $y$ per time unit, which lies above the common reservation wage. If unemployed, they obtain $z$ as net unemployment benefit. The individuals maximize the present value of their expected life income while discounting the future with discount rate $r$ and without being able to choose the number of hours worked. On the other market side, there is an infinite number of firms (with measure 1) which maximize expected profits by choosing ex-ante one single wage that they will pay to their staff ${ }^{13}$ Unemployed individuals receive independent wage offers from the stationary wage offer distribution $H(w)$ at an exogenous rate $\lambda$ (job offer rate), whereas when employed they receive independent offers from the same distribution at rate $\lambda_{L}{ }^{14}$ Finally, individuals working can lose their jobs for exogenous reasons at rate $\delta$ (job destruction rate). Since we assume that the number of job offers an individual receives in a specific time interval is Poisson-distributed, there cannot be two offers at the same time. The optimal strategy for the individual is characterized by a reservation wage $w_{R}$, where all offers above $w_{R}$ are accepted and all offers below are rejected. To calculate the reservation wage, we equate the value equations for unemployment and employment and solve for the wage (for details, see the survey Garloff (2003), equation (7) and appendix 6.1, as well as the literature cited there). After some simplifications, we obtain

(1) $w_{R}=z+\left(\lambda-\lambda_{L}\right) \int_{w_{R}}^{w^{o}} \frac{1-H(w)}{r+\delta+\lambda_{L}(1-H(w))} d w$

where $w^{o}$ represents the maximum of the wage offer distribution. Intuitively, the reser-

\footnotetext{
${ }^{12}$ The term search friction summarizes the facts that unemployed individuals cannot find a job immediately, that employed individuals cannot change their job immediately and that jobs can end for exogenous reasons.

${ }^{13}$ Another possibility how the equilibrium can be achieved is that every company decides for each new contact randomly which wage to offer from the wage offer distribution. However, in general it is assumed that this violates intra firm fairness constraints. (see Bontemps, Robin, and Van den Berg (2000))

${ }^{14} \mathrm{~A}$ job offer means that an individual and a firm meet, that the firm makes its wage offer and that the individual decides whether to accept or not.
} 
vation wage is the higher, the higher unemployment benefits are and the better the job perspectives off-the-job are as compared to on-the-job. The term under the integral represents the average surplus of the value of an employment above $w_{R}$ compared to the value of unemployment. The reservation wage characterizes the behavior of the unemployed. The behavior of employed persons is characterized by the fact that they change jobs if they receive a job offer above their current wage (see Mortensen and Neumann (1988)).

Now, the behavior of firms has to be discussed (see Garloff (2003) for details). Firms maximize profits given by the profit per employee $(y-w)$, where $y$ denotes the output per worker, times the number of employees $(l(w)) \cdot{ }^{15}$ In order to deduce the equilibrium number of employees, consider the dynamics for the firms that pay wages above $w$. They gain new employees from the pool of unemployed and from the pool of firms that pay wages below $w$, while they lose employees only through exogenous shocks. From these dynamics we can derive both the distribution of paid wages in a cross section of workers $(G(w))$ and the equilibrium amount of workers employed in a firm paying a wage $w(l(w))$. Since firms that pay higher wages are able to attract workers from competing firms, $l(w)$ is increasing in $w$.

For firms, it does not pay off to offer wages below $w_{R}$ since workers will never accept and so these firms will have no staff. In equilibrium, firms always pay wages above $w_{R}$. To solve the model for the equilibrium wage offer distribution, the profits of enterprises at the reservation wage (which can be shown to be paid in any case, see Bontemps, Robin, and Van den Berg (2000)) are set equal to the profits for some other point in the support of the wage offer distribution. This yields the equilibrium wage offer distribution, which all individuals with a job offer face,

$$
H(w)=\left\{\begin{array}{cl}
0 & \text { for } \quad w<w_{R} \\
\frac{\lambda_{L}+\delta}{\lambda_{L}}\left(1-\sqrt{\frac{y-w}{y-w_{R}}}\right) & \text { for } \quad w_{R} \leq w<w^{o} \\
1 & \text { for } \quad w \geq w^{o}
\end{array}\right\}
$$

This equilibrium exhibits the following properties: First, identical (三 equally productive) individuals are not paid according to their marginal productivity but they face a whole range of wages at which they can be employed. In addition, all offered wages are strictly below $y$ if there are frictions ${ }^{16}$ Second, the amount of frictions determines the unemployment rate $u r=\delta /(\delta+\lambda)$, where $\delta$ denotes the job destruction rate and $\lambda$ the job offer rate for unemployed. Third, the equilibrium wage offer distribution does

\footnotetext{
${ }^{15}$ The price of output is normalized to 1 .

${ }^{16}$ This can be seen from the upper bound of the wage offer distribution, which is given by $w^{o}=$ $y-\left(y-w_{R}\right)\left(\frac{\delta}{\delta+\lambda_{L}}\right)$.
} 
not depend upon $\lambda$, the job arrival rate for the unemployed, since all that matters are job-to-job changes ${ }^{17}$

Now, assume that a labor union is able to set a minimum wage $w_{\min }$ cutting the wage distribution at this point. Then, the wage offer distribution is cut at that point as well and the reservation wage in the analysis above is replaced by the union minimum wage 18 Since the upper part of the wage distribution also depends on the reservation wage, it follows that the whole distribution changes in response to the introduction of the union minimum wage. In the new equilibrium, all firms still have the same profits but the level of profits is lower than before, while employment remains the same.

Regarding the Krugman hypothesis, note that equilibrium unemployment does not change in response to changes of the minimum wage as long as the latter does not exceed the marginal productivity of the individuals affected 19 In the model, this is the case since in general firms make positive profits even after the introduction of the minimum wage and so it pays off for the firms to raise their wage offer above the new minimum wage.

The variance of the distribution of paid wages depends on two determinants: The first determinant and necessary condition for wage dispersion among identical workers is a positive job offer rate for employed job seekers. It is intuitively clear that the more often individuals are able to change jobs because of wage differences, the more difficult it is for firms to pay low wages since then they quickly lose their staff. This means that the variance of wages decreases with the job offer rate. With the possibility of instantaneous job changes, the wage distribution degenerates to a mass point at the marginal productivity, thus being back to the classical model. The second determinant of the variance of wages is the job destruction rate. The higher this rate, the more frequently employees lose their jobs and become unemployed. Hence, the search friction is higher and the variance of the wage distribution is larger. This is the case, since the trade-off for low-wage firms improves through higher inflows from unemployment.

In what follows, we will formalize the determinants of the variance of the distribution of paid wages $(G(w))$. From equation (2) and from the equations characterizing the flow

\footnotetext{
${ }^{17}$ This can be understood by recognizing that the effects from higher outflows from unemployment and from lower unemployment are exactly offsetting in equilibrium.

${ }^{18}$ In general the reservation wage reacts as well upon the introduction or increase of the binding minimum wage, since then wage offers are higher on average. However, the increased reservation wage remains below the minimum wage.

${ }^{19}$ Obviously, the same is true for the classical model. But, in the classical framework, if a minimum wage is binding, there are always people whose marginal productivity is below this minimum wage, since everybody is paid its marginal productivity. So, the crucial difference is that, under the frictional point of view, people are not paid their marginal productivity, and therefore a binding minimum wage does not necessarily mean higher unemployment.
} 
equilibria, we can calculate the variance of the distribution of paid wages for identical individuals. It is given by (see Van den Berg and Ridder (1993), p. 48ff.)

$$
\operatorname{var}_{G}(w)=1 / 3\left(y-w_{m i n}\right)^{2} \eta(1-\eta)^{2}
$$

where $\eta=\frac{\delta}{\delta+\lambda_{L}}$ is a friction indicator often used in the search literature ${ }^{20}$ Simple comparative static calculations reveal that the variance is increasing with $\delta$ and decreasing with $\lambda_{L}$ if $\eta>1 / 3$. Thus, only if the job offer rate on-the-job is less than twice the job destruction rate, then the effect of $\eta$ on the variance is unambiguously positive. We believe this to be a natural condition to hold, since in Germany job-to-job changes occur less frequently than transitions from employment to nonemployment (see table 2 in our companion paper Fitzenberger and Garloff (2004)). We assume that, typically, this condition is satisfied in the data thus allowing us to test empirically between the two theoretical approaches.

Again, we summarize the empirical implications in a proposition which clarifies the differences to the heterogeneity hypothesis in the marginal productivity theory.

Proposition 2 (Frictional Hypothesis): If the job offer rate on-the-job increases or the job destruction rate declines, then the residual wage dispersion decreases and the cell-specific unemployment rate declines. There is no clear relationship between the job offer rate off-the-job and wage dispersion, but unemployment decreases with an increase in the job offer rate off-the-job. Wage dispersion itself does not affect transition rates.

\section{Testing the Heterogeneity Hypothesis and the Frictional Hypothesis}

We will examine whether the theoretical approaches discussed above are consistent with data for Germany. In the following, we first describe the dataset used. Then, we provide some descriptive results. Finally, we scrutinize the testable predictions for the relationship between transition rates, wage dispersion, and unemployment.

\footnotetext{
${ }^{20} \eta$ is the proportion of jobs that end for exogenous reasons among the sum of job destructions and offers for a job-to-job change. The higher this share, the more unfavorable is the situation for the employees, since jobs end quite fast for exogenous reasons before the individuals can climb the wage ladder.
} 


\subsection{Data}

The empirical analysis is based on the IAB employment subsample (IABS), a large administrative data set for Germany for the time period 1975 to 1997, see Bender, Haas, and Kloose (2000). The IABS contains information from two sources. The first source is the employment statistic based on the integrated notification procedure for health insurance, social security, and unemployment insurance. This way, employers are required to report employment under the social security system which covers about $80 \%$ of all employees. Civil servants, self-employed, helping family, students, and employees earning less than a certain low threshold income are not covered by the system. The second source for the IABS are the transfer payments to the unemployed.

The two sources are merged together for a one percent random sample of employees from the social security records. Therefore, by construction, the dataset is representative regarding employment covered by the social security system but not regarding unemployment. The information on timing (daily!) of being in one labor market state (spells) and on the gross daily wage (rounded to DM) are exact, except for the wage being censored at the upper social security threshold. Typical panel data problems like panel mortality or commemoration error do not arise. In addition, the dataset is big (about 8 millions observations) and representative for all persons who have been employed at least once in a job that is part of the compulsory notifying procedure in the observed 22 years (more than the $80 \%$ in a cross section of workers ${ }^{21}$ ). In the dataset we can observe three states: employed, recipient of transfer payments (i.e. unemployment benefits, unemployment assistance and income maintenance during participation in training programs) and out of sample ${ }^{22}$ Unfortunately, none of the two last categories corresponds exactly to the economic concept of unemployment. The second state is likely to approximate unemployment better than the third one, since every person being recipient of transfer payments is indeed unemployed from an administrative point of view ${ }^{23}$ On the other hand, there are persons who are registered unemployed but who are not entitled to receive transfer payments. During this time, these people are not recorded in the IABS. Thus, they cannot be distinguished from the self-employed, civil servants, people being out of labor force and others (see above) who are at least

\footnotetext{
${ }^{21}$ The share is also higher for the full-time employed used in our empirical analysis.

${ }^{22}$ In addition, we could distinguish between people being out of sample between two spells of different states and between people who are at one point in time not in the dataset, but where there is no spell either before or afterwards (broad definition). At the extreme, the latter might include persons who are dead, whereas the former does not. For most analyses, we use the narrow definition of the third state, i.e. only out of sample spells where there are spells of different states as well afterwards as before.

${ }^{23}$ With the exception of participants in a training program. We basically view them as being unemployed since the goal of the program is to improve the reemployment chances in the future.
} 
once employed in a recorded job during the time period investigated.

We calculate transition rates between the three states. Transitions from employment to receiving transfer payments are interpreted as transitions to unemployment ${ }^{24}$ since the benefit entitlement period is six months, already after an employment spell of six months, and it increases to one year after a two year spell of employment. In contrast, transitions from unemployment into employment are not that easily approximated by transitions from receiving transfer payments to employment. Long-term unemployed, whose benefits are exhausted, might find a job, and there might be people shifting from the state receiving transfer payments to the state out of sample by becoming a civil servant or by becoming self-employed. Therefore, in the empirical section, we use different definitions of unemployment to check for consistency of the results.

For our empirical analysis, we use only full-time working men who are between 25 and 54 years old and who are residents in West Germany. This sample is grouped into cells by age, education, and year. We define three education groups: The first category corresponds to persons who have neither a completed vocational training nor a university degree. The second category are people who have finished a vocational training but have no university degree. The third group corresponds to persons who have a university degree or a degree from a technical college ("Fachhochschule") ${ }^{25}$ We also group the individuals by their age in ten three-years-intervals (25-27, 28-30, etc.) to proxy for potential experience. For the descriptive analysis, we use the cells for all 22 years (1975-1997). For the explicit empirical test of the two hypotheses, we restrict ourselves to the 17 years 1980-1997, since there are concerns that the transition rates cannot be estimated consistently for the seventies (see Bender, Haas, and Kloose (2000)). Annual transition rates are based on the labor market state on January 1st of each year. The within wage dispersion is calculated for the cross section of workers in each age-education cell for the 22 (17) years. When wages are censored from above, we replace the censored value by the predicted value from a Tobit regression (run separately for every age-education cell in every year) assuming that log-wages are normally distributed in a cell.

\subsection{Descriptive Evidence}

\footnotetext{
${ }^{24}$ The largest group of workers not contained in the dataset are civil servants who are typically tenured (三 no risk of unemployment).

${ }^{25}$ Notice that the education information in the IABS-dataset is not always consistent over time so that we corrected the education information based on the simple rule that a finished degree cannot be lost.
} 
This section provides descriptive evidence on the transition rates and the wage structure. Further detailed results can be found in our companion paper Fitzenberger and Garloff (2004). First, we calculate the transition rates between the three labor market states and the rate of job-to-job changes for each of the thirty cells by year. Several testable hypotheses regarding the relationship between theses rates and age or education are plausible. According to the frictional hypothesis, one might argue that the job changing rate is higher for the better educated, since search techniques improve with higher education. Since people sort themselves in better paying jobs as time progresses, we expect that job changing rates decrease with age. As far as the job finding rate is concerned, one might argue that people who are older have higher reservation wages because they had higher wages before (see e.g. Christensen (2003)). Again, with higher education the informational situation might be better. ${ }^{26}$ According to the heterogeneity hypothesis, it is not clear whether job changes take place more often with a higher education. For older workers, we expect less job changes due to a higher level of specific human capital at risk. The same holds for the transitions to unemployment since we suspect that their high dismissal protection (see Franz (2003), p. 251) makes firing them more unlikely. Based on the heterogeneity hypothesis, we expect the reemployment probability for those who receive transfer payments to decrease in age for institutional reasons since the length of benefit entitlement increases in age.

Table 1 summarizes the transitions between the three states and their variation with age and education using simple OLS-regressions. The reference category consists of employees with lower education, aged 25-27. Job changes are more frequent for higher educated individuals than for lower educated individuals and they occur less frequently as individuals get older ${ }^{27}$ Likewise, the probability of remaining employed is higher for higher education groups and for older individuals. As confirmed by other studies (see e.g. Lauer (2003)), we observe the highest job stability not for university graduates but for individuals with a vocational training degree. The probability of staying at the same job is smaller for higher education groups but grows with age. The probability for returning from receiving transfer payments to employment increases with the education level and decreases with age, while likewise the probability of remaining recipient of transfer payments increases with age and decreases with educational level. Finally, once out of the sample, individuals return more often to employment when they hold a vocational degree and more rarely when they finished university. It decreases with age but seems to have a minimum at the age of 40 to 45 . Finally, individuals with a

\footnotetext{
${ }^{26} \mathrm{~A}$ related argument of why the job finding rate might be higher for high-skilled individuals is given in Moen (1999). Here the basic idea is that there might be several job applicants for one vacancy at a time and that the person with the highest skill will always get the job.

${ }^{27}$ As a quantitative example, having a university degree as compared to having no degree at all is associated with a $3.4 \%$ higher rate of job change.
} 


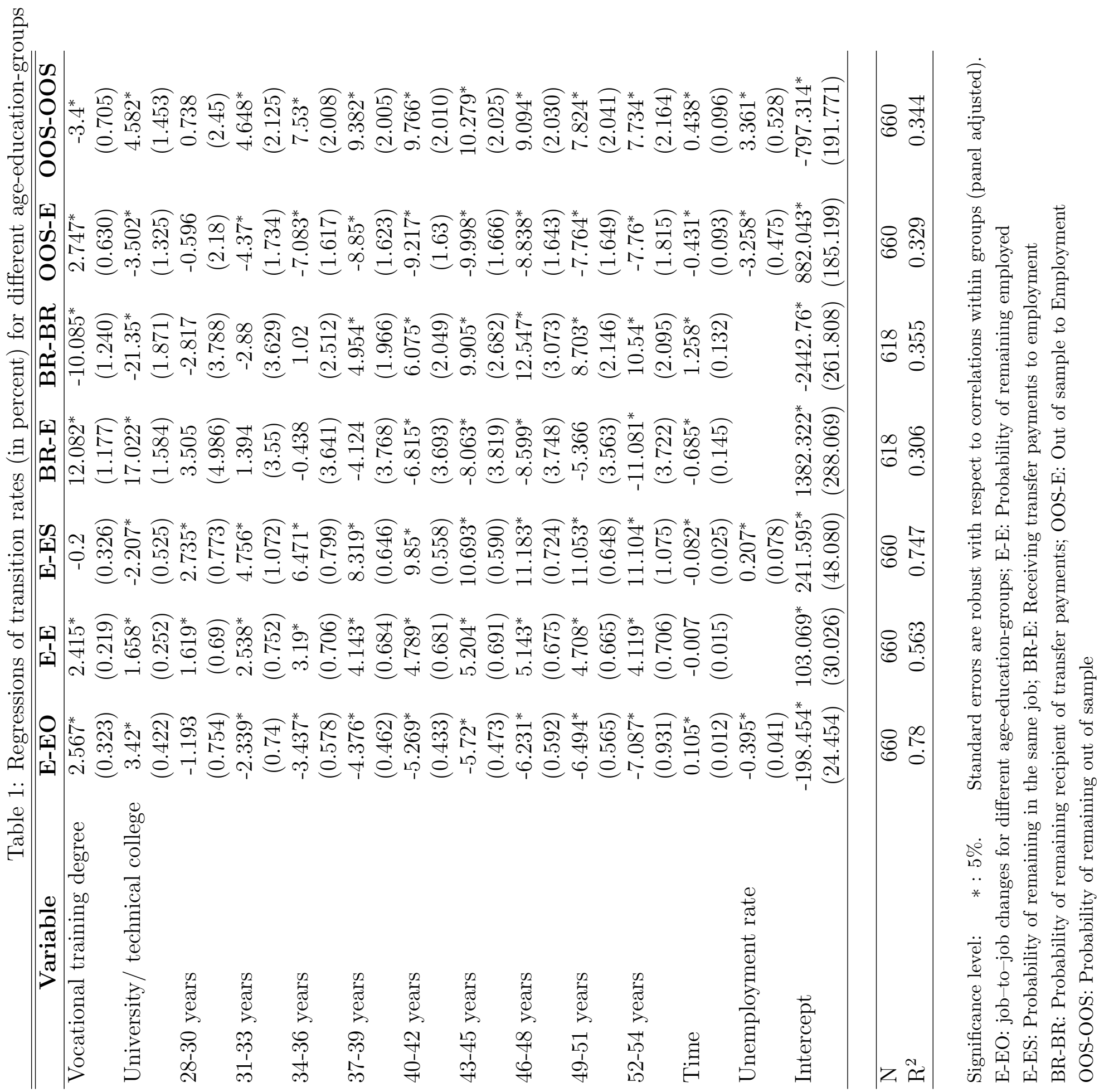


vocational degree stay less often out of sample while university graduates stay more often out of sample ${ }^{28}$ The probability of remaining there increases with age and has a maximum in the $40 \mathrm{~s}$.

We conclude that most findings discussed so far are consistent with both hypotheses of the labor market, as put forward above, although e.g. job-to-job transitions are not easily explained in a neoclassical framework. Since job-to-job changes are a crucial aspect in equilibrium search theory, we explore them in more detail. We defined jobto-job changes as a change of the employer with an intervening out-of-sample spell lasting not longer than 15 days 29

Table 2: Transitions within categories

\begin{tabular}{c|c|c|c|c} 
& Total & Share winners & Share losers & No change \\
\hline Full-time to full-time & 282644 & 0.638 & 0.289 & 0.073 \\
Part-time 1 to part-time 1 & 13375 & 0.643 & 0.291 & 0.066 \\
Part-time 2 to part-time 2 & 2217 & 0.549 & 0.289 & 0.162 \\
\hline
\end{tabular}

\begin{tabular}{c|c|c|c} 
& $\begin{array}{c}\text { Relative gain } \\
\text { of the winners }\end{array}$ & $\begin{array}{c}\text { Relative loss } \\
\text { of the losers }\end{array}$ & $\begin{array}{c}\text { Overall } \\
\text { wage change }\end{array}$ \\
\hline Full-time to full-time & 0.268 & -0.152 & 0.127 \\
Part-time 1 to part-time 1 & 0.205 & -0.143 & 0.09 \\
Part-time 2 to part-time 2 & 0.268 & -0.162 & 0.101 \\
\hline
\end{tabular}

part-time 1: working hours are more than $50 \%$ of regular working hours part-time 2: working hours are less than or equal to $50 \%$ of regular working hours

We consider wages before and after job change, distinguish between winners and losers and calculate the mean gain or loss from the job-to-job change. We find (see table 2 that in general the gains and losses from job-to-job changes are remarkable. On average, winners earn about $25 \%$ more, while losers still earn around $15 \%$ less. Almost two thirds have an effective gain from changing jobs while more than $25 \%$ lose. In general, the position in terms of gains and losses is better for higher educated than for lower educated individuals. An exception is the share of winners, which is smaller for higher education. The relative position across different educational attainments deteriorates with age. An exception is the share of losers, which is on average smaller for older individuals. The high gains and the high share of winners point to the central

\footnotetext{
${ }^{28}$ Reasons might be that a university degree often is a prerequisite for becoming civil servant and that university graduates more often become self-employed.

${ }^{29}$ We restrict our analysis to direct job-to-job changes (new job starts within 15 days after end of old job), since we are interested in the wage effects of voluntary transitions. For an analysis of wage effects of job-to-job transitions on an annual basis, see Pfeiffer (2003). His main findings that the wages of job changers are more dispersed than the wages of job stayers are in accordance with our results.
} 
role of the wage in understanding job-to-job changes 30 On the other hand, there is a remarkable share of persons with losses. This result is difficult to reconcile with search theory. Still, the decreasing gains from such changes with age can be understood by sorting processes into higher paying jobs. The fact that relative losses do not increase with age is difficult to reconcile with the notion that specific capital should be more important at a higher age ${ }^{31}$ As far as the relationship between education and winner/loser shares as well as relative gains or losses are concerned, the hypotheses discussed above do not allow to rationalize our findings.

Finally, we investigate all persons in one cell who are employed in two consecutive years. They were classified in deciles in the wage distribution each year. So we observe a 10x10-matrix for each education-by-age cell and each year. To summarize the information, we analyze the determinants of changing the relative position in the wage distribution. We estimated an ordered probit model where the options were moving one or more deciles up, remaining in the same decile or moving one or more deciles down. Since replacing year-dummies by a linear time trend did not change our results, table 3 only reports the latter results.

According to table 3, upward wage mobility decreases with age and increases with education. As expected, job-to-job changers have a higher probability to move up the wage distribution. As individuals age, upward wage mobility is considerably less likely, even when changing jobs which also occurs more rarely. Finally, the interquantile range (iqr) between the eighth and the second decile (in logs) exhibits a negative impact on upward wage mobility, i.e. the higher the wage dispersion the lower is the probability of moving up the wage ladder. Still, the findings that job changers have better career opportunities and that older individuals perform worse are consistent with the frictional hypothesis.

\subsection{The Relationship between Transitions and Wages}

After presenting some pertinent descriptive evidence, we now turn to a more rigorous test whether residual wage dispersion is related to heterogeneity or to labor market frictions. We start by restating the central ideas of both hypotheses. On the one hand, if wages are basically determined by residual heterogeneity under the heterogeneity hypothesis, we expect that low wage dispersion is a sign for high union influence, which means that there is high unemployment and that entry rates into unemployment are

\footnotetext{
${ }^{30}$ Similarly, Fitzenberger and Spitz (2004) find that the wage plays a central role in explaining occupational changes.

${ }^{31}$ Of course, this argument relies on the fact that age is positively correlated with tenure.
} 
Table 3: Decile changes between two consecutive years

\begin{tabular}{lcc}
\hline \hline \multicolumn{1}{c}{ Variable } & Coefficient & (Std. Err.) \\
\hline 28-30 years & $-0.1492^{*}$ & $(0.036)$ \\
31-33 years & $-0.2148^{*}$ & $(0.039)$ \\
34-36 years & $-0.2663^{*}$ & $(0.039)$ \\
37-39 years & $-0.3084^{*}$ & $(0.039)$ \\
40-42 years & $-0.3877^{*}$ & $(0.041)$ \\
43-45 years & $-0.4211^{*}$ & $(0.044)$ \\
46-48 years & $-0.4530^{*}$ & $(0.057)$ \\
49-51 years & $-0.4786^{*}$ & $(0.054)$ \\
52-54 years & $-0.5242^{*}$ & $(0.003)$ \\
Time & 0.0040 & $(0.048)$ \\
Vocational training degree & $0.2756^{*}$ & $(0.038)$ \\
University/ technical college & $0.2540^{*}$ & $(0.010)$ \\
Job change dummy & $0.3388^{*}$ & $(0.027)$ \\
Job change x 28-30 years & 0.0002 & $(0.016)$ \\
Job change x 31-33 years & $-0.0335^{*}$ & $(0.011)$ \\
Job change x 34-36 years & $-0.0507^{*}$ & $(0.014)$ \\
Job change x 37-39 years & $-0.0819^{*}$ & $(0.012)$ \\
Job change x 40-42 years & $-0.1344^{*}$ & $(0.019)$ \\
Job change x 43-45 years & $-0.1014^{*}$ & $(0.015)$ \\
Job change x 46-48 years & $-0.1252^{*}$ & $(0.015)$ \\
Job change x 49-51 years & $-0.1140^{*}$ & $(0.02)$ \\
Job change x 52-54 years & $-0.1277^{*}$ & $(1.127)$ \\
iqr/1000 & -0.4190 & $(5.154)$ \\
EE/10000 & $-0.7428^{*}$ & $(5.554)$ \\
_cut1 _cut2 & 6.8558 & \\
\hline
\end{tabular}

\begin{tabular}{lc}
\hline $\mathrm{N}$ & 991041 \\
Log-likelihood & -966348.106 \\
$\chi_{(24)}^{2}$ & 25642.882 \\
\hline
\end{tabular}

Significance level: $\quad *: 5 \%$

Standard errors are robust with respect to correlations within groups (panel adjusted).

high while exit rates out of unemployment are low. On the other hand, the frictional hypothesis postulates that wages in one cell are determined by the amount of search frictions. If wage dispersion is low, then both search frictions and unemployment are low as well. Either the effect of search frictions can be direct via the job destruction rate which is positively related with wage dispersion and unemployment. Or an indirect effect originates from the fact that the job offer rate on-the-job (which negatively affects wage dispersion) and off-the-job (which negatively affects unemployment) are likely to be positively correlated. 
Regarding the heterogeneity hypothesis, the relevant variables can be directly measured. We will regress transition rates and the unemployment rates on our measure of wage dispersion. For the frictional hypothesis, on the contrary, it is more difficult since the relevant variables are not observable. First, we do not observe the job offer rate on-the-job but only the job-to-job transition rate. Under the assumptions of the search model, individuals change jobs if the wage offer exceeds the current wage (see Mortensen and Neumann (1988)), i.e. the probability of changing a job is given by $\lambda_{L}(1-H(w))$ where $w$ is the wage an individual currently earns. So, if the wage offer distribution were constant, the transition rate would be proportional to the job offer rate. However, the wage offer distribution varies with the job offer rate. An increase in the latter shifts the wage offer distribution towards the marginal productivity of the individuals, thus typically reducing the wage dispersion. We assume that the direct effect dominates i.e. an increase in the job offer rate results in a higher jobto-job transition rate. The second variable which determines the wage dispersion is the job destruction rate. Again, it is not possible to distinguish between voluntary quits and job destructions due to exogenous reasons ${ }^{32}$ However, as often done in the empirical literature, we use the entry rate into unemployment to identify exogenous job destruction (see e.g. Van den Berg and Ridder (1998)). To check for robustness, we use different definitions when calculating the entry rate into unemployment.

To operationalize wage dispersion, we use the interquantile range (iqr) between the eighth and the second decile of log wages. This is a more robust measure compared to the sample variance (or its Tobit estimate) in a cell because of the censoring in the wage data. For medium and low skilled worker, iqr is not affected by censoring for the vast majority of cells. However, for high skilled workers censoring is quite prevalent at the eighth decile and, therefore, we omit high skilled worker from the analysis in this section 33 According to the heterogeneity hypothesis, a smaller iqr reflects stronger wage compression. Then, the unemployment rate, either measured by recipients of transfer payments or by these plus individuals being out of sample, is high, while we observe few transitions from receiving transfer payments to employment and a lot of transitions out of employment. Based on the frictional hypothesis, we predict that an increase in job-to-job transitions or a reduction in transitions from employment to receiving transfer payments result in a smaller iqr. Correspondingly, the share of recipients of transfer payments or the share of recipients of transfer payments plus

\footnotetext{
${ }^{32}$ This includes every reason which makes the previous job unprofitable which is beyond the influence of the employer or the employee. This precludes, however, the voluntary decision to become unemployed or the decision of the employer to lay off somebody who is enduringly unproductive. To check for consistency in our approach we allow for different definitions of unemployment.

${ }^{33}$ We also performed the analysis including high skilled workers (the eighth decile relies on our Tobit estimates) which did not alter the main results. These results are available upon request.
} 
individuals being out of sample should decline.

The empirical analysis is based on a panel of 20 education-by-age cells which are observed over 17 years. Using fixed-effects estimation techniques, we allow for cell-specific effects in wage dispersion, transition rates, and unemployment. It is quite likely that these cell-specific effects are both correlated with the dependent variable and the regressor variables, thus precluding estimating a random-effects model. However, two reasons for endogeneity are particularly noteworthy since they might not be addressed completely by estimating a fixed-effects model. First, endogeneity problems arise from the very fact that each transition from and to employment affects the wage distribution depending upon the type of selectivity of the transition with respect to the position in the wage distribution. This is an issue when individuals in a cell are still heterogeneous in their productivity (heterogeneity hypothesis). However, the sign of the empirical correlation between changes in transition rates and the wage dispersion measure should not differ from the sign of the causal effect because of the likely reaction of unions to changes in employment prospects. ${ }^{34}$ A second reason is that the two theories postulate a different direction of the causal relationship between transition rates and wage dispersion 55 In the following, we try to address this by using lagged regressors of the potentially endogenous explanatory variables. This means that, when estimating the impact of transition rates on wage dispersion, we use the rates from year $t-1$ to year $t$ to measure the impact on wage dispersion in year $t$ and vice versa. Another reason why the endogeneity, coming from the direct reverse causation of the theories, is not harmful to our approach is the following. Suppose that either the heterogeneity or the frictional hypothesis holds. Suppose further that we empirically reject, for instance, the heterogeneity hypothesis. Then, we reject it either because it is wrong which means that the frictional hypothesis is correct or because we have endogeneity, which also implies that the frictional hypothesis is correct. Therefore, rejection implies both endogeneity and that the heterogeneity hypothesis is wrong. On the other hand, we can not err by accepting the heterogeneity hypothesis because endogeneity coming from reverse causation, implies that the frictional hypothesis is correct. The latter implies a different direction of correlation. To illustrate this argument with an example: Assume

\footnotetext{
${ }^{34}$ Take the following example: Consider a positive productivity shock, then employment prospects will improve and therefore transition rates into employment increase, it typically follows that wage dispersion increases, as a first order effect, for given union contract wages. In response, unions will raise contract wages effectively reducing wage dispersion in response. If unions trade off average wages and employment in their utility function, then both wage dispersion and transition rates into employment (and correspondingly the employment rate) are still higher in the end compared to the situation before the exogenous increase in transition rates. This follows from standard textbook models of wage bargaining.

${ }^{35}$ Strictly speaking, the heterogeneity hypothesis focuses on $\lambda$ and the frictional hypothesis on $\lambda_{L}$. However, they are likely to be strongly positively correlated.
} 
that we regress the job destruction rate on iqr. The heterogeneity hypothesis predicts a negative sign. Suppose that according to the frictional hypothesis the true sign is positive. Then, it is not possible to find a negative sign because of the endogeneity from the frictional hypothesis, since this implies a positive correlation between iqr and jdr and therefore the bias would go into the opposite direction.

To circumvent problems stemming from the fact that both the transition rates and the wage dispersion measure have bounded support, we use positive monotone transformations of these variables on the left hand side that are unbounded. That is, we use the transformation $l i q r=\ln (i q r)$ for the interquantile range, and the transformation $\operatorname{tr}=\ln ($ rate $/(1-$ rate $))$ for the transition rates.

We estimate the model as a fixed-effects feasible GLS-model (FEGLS), see Wooldridge (2002, chapter 10.5.5) ${ }^{36}$ Consider the following model estimated to test the heterogeneity hypothesis:

$$
t r_{i t}=\alpha+i q r_{i t} \beta+c_{i}+u_{i t}
$$

for cells $i=1, \ldots, 20$ and year $t=1980, \ldots, 1996$. $i q r_{i t}$ is the interquantile range, $t r_{i t}$ is the transformation $\ln \left(\right.$ rate $_{i t} /\left(1-\right.$ rate $\left.\left._{i t}\right)\right)$, with rate $_{i t}$ being the transition rate from $t-1$ to $t, \alpha$ the intercept, $c_{i}$ the unobserved heterogeneity, which is assumed constant over time, and $u_{i t}$ represents the unsystematic error component. In addition, equation (4) includes year dummies to control for business cycle effects ${ }^{37}$ Estimation proceeds in two steps. First, we estimate equation (4) by fixed effects. We then calculate the empirical covariance matrix of the fixed effects residuals. After omitting one equation, since the covariance matrix of the fixed-effect-residuals does not have full rank (see Wooldridge (2002), chapter 10.5.5), the remaining covariance matrix is used for the GLS transformation. Second, we estimate the transformed model. Table 4 comprises the result of the second stage 38

\footnotetext{
${ }^{36}$ We started with implementing both the standard fixed-effects estimator and the estimator in first differences. Typically, both variants seemed inefficient since the associated error terms after the fixedeffects and the first-differences transformation, respectively, still showed considerably autocorrelation and the precision of the estimates was quite low. The results for fixed effects and first differences are available upon request.

${ }^{37}$ See Wilke (2004) for the importance of business cycle effects on transition rates in Germany.

${ }^{38}$ Note that estimating equation (4) as a system of equations would not result in an efficiency gain, since we use the same regressors in all equations. (see Wooldridge (2002), chapter 7.3)
} 
Table 4: FEGLS-regressions of the (transformed) transition rates on the lagged interquantile range (Heterogeneity hypothesis)

\begin{tabular}{|c|c|c|c|}
\hline Dependent variable & $\begin{array}{l}\text { Coefficient } \\
\text { estimate } \beta\end{array}$ & $\begin{array}{c}\text { Standard } \\
\text { error }\end{array}$ & $\begin{array}{c}\text { Expected } \\
\text { sign }\end{array}$ \\
\hline jdr1 (E-BR) & 0.0259 & 0.1198 & - \\
\hline jdr2 (E-BR|OOS) & -0.0595 & 0.0683 & - \\
\hline jdr3 (E-NoE) & $-0.1265^{*}$ & 0.0478 & - \\
\hline jfr1 (BR-E) & $-1.7274^{*}$ & 0.2782 & + \\
\hline jfr2 (BR|OOS-E) & $-0.8449^{*}$ & 0.2159 & + \\
\hline jcr $(\mathrm{E}-\mathrm{EO})$ & $0.2516^{*}$ & 0.0400 & 0 \\
\hline
\end{tabular}

*indicates that the coefficient is significant on the $5 \%$ significance level. See appendix for the definition of the variables. The results for the year dummies have been suppressed from the table for readability. The estimation is based on 340 observations. Further explanations are given in the text.

The signs for different definitions of the job destruction rate (jdr1-jdr3) confirm in two out of three cases the heterogeneity hypothesis. It is significant, however, only for the broadest definition of entries into unemployment. From this it is not clear, whether an increasing wage dispersion indeed reduces transitions from employment to unemployment, as predicted by the heterogeneity hypothesis. The estimated coefficients for both definitions of the job finding rate (jfr1, jfr2) are significantly negative and contradict therefore the heterogeneity hypothesis. We expected that a higher wage dispersion would imply that unemployed find jobs faster, since there are more jobs that fit the marginal productivity of the searching individuals. This seems not to be the case in Germany. The wage dispersion was not expected to have any effects on the job changing rate (jcr). The data, however, contradict this view as well. The higher the wage dispersion the higher is the job changing rate. Finally, we also explore directly the relationship between unemployment and wage dispersion, which is the focus of the heterogeneity hypothesis. For the narrow definition of unemployment (recipients of transfer payments only) $u$, we find a positive sign, but it is not significant. Including the state out of sample (variable $\tilde{u}$ ) increases slightly the size of the effect, it remains however insignificant. For both definitions the sign contradicts the heterogeneity hypothesis since higher wage dispersion is associated with higher nonemployment or at least with no employment change. In the light of our previous findings, this implies that the negative effect of the wage dispersion on the job finding rate dominates other effects that drive (equilibrium) unemployment and that may counteract this link. Thus, the heterogeneity hypothesis seems not to perform very well if confronted with the data and, in particular, it is in contradiction to the lack of a significantly negative coefficient 
for unemployment. Though not being significant, the positive coefficient estimates are consistent with the frictional hypothesis.

Table 5: FEGLS-regression of (different definitions of the transformed) unemployment rates on the (lagged) interquantile range (Heterogeneity hypothesis)

\begin{tabular}{|c|c|c|}
\hline Dependent variable & $\begin{array}{c}\text { Coefficient estimate } \\
\text { (Standard error) }\end{array}$ & $\begin{array}{c}\text { Expected } \\
\text { sign }\end{array}$ \\
\hline$u$ & $\begin{array}{c}0.0629 \\
(0.0796)\end{array}$ & - \\
\hline$\tilde{u}$ & 0.0658 & - \\
& $(0.0804)$ & \\
\hline
\end{tabular}

The Estimation is based on 320 observations. See appendix for the definition of variables. Further explanations are given in the text.

Next considering the frictional hypothesis directly, we investigate whether the transition rates affect the (logarithm of the) interquantile range in the expected direction. Our estimated model is specified as

(5) liqr $_{i t}=\alpha+$ rate $_{i, t-1} \beta+c_{i}+u_{i t}$,

where $i=1, \ldots, 20$, and $t=1980, \ldots, 1996$. Again, year dummies are included to control for business cycle effects. The model is estimated by FEGLS. Table 6 contains the results for estimating equation (5) regressing the transformed interquantile range on the transition rates. 
Table 6: FEGLS-regressions of the (logarithm of the) interquantile range on the lagged transition rates from period ( $\mathrm{t}-1$ ) to $\mathrm{t}$ (Frictional hypothesis)

\begin{tabular}{|c|c|c|c|c|c|c|}
\hline $\begin{array}{l}\text { Coeff. estimate } \\
\text { (Stand. error) }\end{array}$ & $\begin{array}{c}\text { jdr1 } \\
(\mathrm{E}-\mathrm{BR})\end{array}$ & $\begin{array}{c}\text { jdr2 } \\
(\mathrm{E}-\mathrm{BR} \mid \mathrm{OOS})\end{array}$ & $\begin{array}{c}\text { jdr3 } \\
(\mathrm{E}-\mathrm{NoE})\end{array}$ & $\begin{array}{c}\text { jcr } \\
(\mathrm{E}-\mathrm{EO})\end{array}$ & $\begin{array}{c}\text { jfr1 } \\
\text { (BR-E) }\end{array}$ & $\begin{array}{c}\text { jfr2 } \\
(\mathrm{BR} \mid \mathrm{OOS}-\mathrm{E})\end{array}$ \\
\hline liqr & $\begin{array}{c}0.9106^{*} \\
(0.1099)\end{array}$ & $\begin{array}{c}0.7693^{*} \\
(0.0907)\end{array}$ & $\begin{array}{r}0.6094^{*} \\
(0.0887)\end{array}$ & $\begin{array}{c}-0.0351 \\
(0.1557) \\
\\
-0.1806 \\
(0.1420) \\
-0.2849^{*} \\
(0.1257) \\
\end{array}$ & $\begin{array}{c}0.1143^{*} \\
(0.0214) \\
\\
0.1199^{*} \\
(0.0181) \\
\end{array}$ & $\begin{array}{c}0.1946^{*} \\
(0.0252)\end{array}$ \\
\hline Exp. sign & + & + & + & - & 0 & 0 \\
\hline
\end{tabular}

See appendix for the definition of the variables. The estimation is based on 320 observations.

The frictional hypothesis purports that the job destruction rate (jdr1-jdr3) should have a positive influence on wage dispersion. This is supported by the data since we find positive signs which are always significant. Obviously, a higher job destruction rate is associated with higher wage dispersion, from the point of view of the frictional hypothesis because higher job destruction increases the monopsony power of the firms via its effect on unemployment. The second prediction concerns the job changing rate (jcr). Here, an increase in the job-to-job transition rate should reduce wage dispersion. The signs found in the data are well in accordance with this hypothesis. However, we find a significant negative effect only when controlling for transitions from employment to unemployment and for transitions from unemployment to employment. Obviously, if people change jobs more often wage dispersion decreases or remains unchanged. Finally, we suspected that the job finding rate (jfr1, jfr2) bears no influence on wage dispersion. This implication is not confirmed. Instead, we find a positive influence of the job finding rate on wage dispersion which always proves significant. When individuals find jobs faster, this seems to increase wage dispersion.

As a second evaluation of the frictional hypothesis, we regress the (logarithm of the) 
wage dispersion measure on the lagged unemployment rate and on the lagged frictions indicator $\eta=\frac{\delta}{\delta+\lambda_{L}}$ (using the job-to-job transition rate for $\lambda_{L}$ ) again under inclusion of year dummies as regressors and using either the narrow or the broad definition of unemployment. The results in table 7 indicate that $\eta$ does not show the expected direction of influence. The frictional hypothesis predicts that wage dispersion rises with a higher amount of market frictions $\eta$. Empirically, however, a higher value for $\eta$ seems to be associated with lower wage dispersion. This must be interpreted as evidence against search theory. Especially, in light of the previous estimation results this is astonishing, since we find that both factors influencing $\eta$, that is, $\delta$ and $\lambda_{L}$ show the correct sign from the point of view of the frictional hypothesis. The results for the two definitions of unemployment are in favor of search theory. Overall, one should be cautious not to overinterpret these results, in particular, since our empirical measure for $\lambda_{L}$ is not exactly the job offer rate on-the-job.

Table 7: FEGLS-regressions of the log of the interquantile range on the lagged frictions indicator and the lagged unemployment rate (Frictional hypothesis)

\begin{tabular}{|c|c|c|c|r|}
\hline $\begin{array}{c}\text { Coefficient estimate } \\
\text { (Standard error) }\end{array}$ & $\eta$ & $\tilde{\eta}$ & $u$ & $\tilde{u}$ \\
\hline iqr & -0.0012 & $-0.5367^{*}$ & 0.1943 & $0.3842^{*}$ \\
& $(0.0171)$ & $(0.1608)$ & $(0.1099)$ & $(0.1116)$ \\
\hline Expected sign & + & + & + & + \\
\hline
\end{tabular}

The Estimation is based on 320 observations. Year dummies are included as regressors. See appendix for the definition of the variables.

Summing up, we conclude that both the heterogeneity hypothesis and the frictional hypothesis are only partly consistent with the data. In a strict sense, both hypotheses are rejected by the data. Taken together, the frictional hypothesis seems to perform better than the heterogeneity hypothesis. Regarding the starting point of our discussion, namely the relationship between wage dispersion and unemployment, our results favor search theory and contradict the Krugman hypothesis regarding residual wage dispersion.

\section{Conclusions}

This paper attempts to discriminate between different theories on the relationship between unemployment and residual wage dispersion. Starting from the Krugman (1994) hypothesis, we develop two hypotheses which exhibit different empirical implications. One view, which we denote heterogeneity hypothesis, is that wages are determined entirely by marginal productivity so that residual wage dispersion corresponds to residual 
productivity dispersion. To account for the institutional setting in Germany we allow labor unions to compress wages from below by imposing different minimum wages for different types of worker. Differences in residual wage dispersion might stem from union influence differing in strength. Accordingly, unemployment results because the minimum wage is higher than the marginal productivity of the unemployed. The alternative view, which we denote frictional hypothesis, is based on search theory. It states that after having controlled for age and education, residual individual heterogeneity is not sufficiently strong to account for the considerable residual wage dispersion. Instead, the residual wage dispersion is determined by the amount of search frictions. If search frictions are high, we will observe a high wage dispersion since search frictions lead to monopsony power for the firms resulting in higher wage dispersion. Accordingly, unemployment is not caused by minimum wages set by labor unions but is a result of the search frictions. Our empirical analysis tests these opposing hypotheses. We obtain panel estimates that are based on the comovement in transition rates, unemployment, and wage dispersion within age-education cells. The results are slightly more supportive for the frictional hypothesis than for the heterogeneity hypothesis. Especially, regarding the relationship between unemployment and residual wage dispersion, the frictional hypothesis seems to perform better. Thus, regarding residual wage dispersion, our results contradict the Krugman hypothesis. A compression of the residual wage dispersion does not have to be associated with an increase in unemployment. Future research should address the challenging issue of estimating the relationship between employment and both between- and within-wage dispersion in a unified framework.

There are a number of critical issues which should be mentioned at the end to put this study into perspective. First, the two hypotheses are complementary in a broad sense. They become mutually exclusive in the sense that the frictional hypothesis postulates 'observable' residual heterogeneity while the heterogeneity hypothesis does not, once productivity related heterogeneity is accounted for. Second, the data do not perfectly match the data requirements. For instance, it would be interesting to investigate whether our (imperfect) wage dispersion measure is correlated with the relative strength of the union membership in a cell. Third, at this level of analysis, we cannot use the primitive variables, which search theory is built upon, e.g. the job offer rate while employed instead of the actual rate of job changes. In this sense, our analysis operate at a descriptive level. However, this has the advantage that it does not require the strong assumptions typically invoked to estimate structural models of search equilibrium. 


\section{Appendix: Definition of Variables used in Empirical Analysis}

1. jdr refers to the job destruction rate and has three different versions:

$j d r 1(\mathrm{E}-\mathrm{BR})$ is the rate of persons that are employed $(\mathrm{E})$ in one year and who receive benefits $(\mathrm{BR})$ in the next year.

$j d r 2(\mathrm{E}-\mathrm{BR} \mid \mathrm{OOS})$ is the rate of individuals who are employed in the first year and receive benefits or are out of sample (OOS, conditional on returning) in the following year.

$j d r 3(\mathrm{E}-\mathrm{NoE})$ includes in the second year also individuals that do not return to the labor market.

2. jfr refers to the job finding rate and has two different versions:

jfr $1(\mathrm{BR}-\mathrm{E})$ is the rate of individuals that receive benefits in one year and who are employed in the next year.

jfr2 (BR $\mid$ OOS-E) comprises both benefit recipients and individuals that are temporarily not in the dataset (i.e. conditional on returning) in the first year.

3. $j c r(\mathrm{E}-\mathrm{EO})$ is the share of individuals that has changed jobs between two consecutive years.

4. When rates are used as left hand side variable in regressions, they are transformed as follows

$$
t r=\log (\text { rate } /(1-\text { rate }))
$$

to insure that the variable is unbounded.

5. The wage dispersion measure iqr is the difference between the log of the eighth decile and the second decile. For the purpose of the regression, on the left hand side, we take the $\log$ of the difference, i.e.

$$
\operatorname{liqr}=\log (i q r)
$$

to ensure that the variable is unbounded. 
6. The unemployment rate $u$ in the narrow definition is defined as

$$
u=\frac{B R}{E+B R+O O S},
$$

and, in the broad definition, $\tilde{u}$ is given by

$$
\tilde{u}=\frac{B R+O O S}{E+B R+O O S} .
$$

As a left hand side variable, we use the transformation $u=\log (u /(1-u))$.

7. The narrow frictions indicator is calculated as

$$
\eta=\frac{j d r 1}{j d r 1+j c r},
$$

while the broad definition is given by

$$
\tilde{\eta}=\frac{j d r 3}{j d r 3+j c r} .
$$




\section{References}

Abowd, J. M., R. H. Creezy, and F. Kramarz (2002): "Computing Person and Firm Effects Using Linked Employer-Employee Data," unpublished manuscript, Cornell University, Ithaca.

Abowd, J. M., F. Kramarz, and D. N. Margolis (1999): "High Wage Workers and High Wage Firms," Econometrica, 67(2), 251-333.

Becker, G. S. (1964): Human Capital. Chicago: University of Chicago Press.

Bender, S., A. HaAs, and C. Kloose (2000): "The IAB Employment Subsample 1975-1995," Schmollers Jahrbuch, pp. 649-662.

Bontemps, C., J.-M. Robin, and G. J. Van den Berg (2000): "Equilibrium Search with Continuous Productivity Dispersion: Theory and Nonparametric Estimation," International Economic Review, 41(2), 305-358.

Burdett, K., and D. T. Mortensen (1998): "Wage Differentials, Employer Size, and Unemployment," International Economic Review, 39(2), 257-273.

Cahuc, P., And A. Zylberberg (2001): Le Marché du Travail. Brussels: De Boeck and Larcier s.a.

Card, D., F. Kramarz, and T. Lemieux (1999): "Changes in the Relative Structure of Wages and Employment: A Comparison of the United States, Canada, and France," Canadian Journal of Economics, 32(4), 843-877.

Christensen, B. (2003): "Selektionsverzerrungen, erfragte Reservationslöhne und Arbeitslosigkeitsdauer," Kiel Working Papers No. 1162, Kiel Institute for World Economics (IFW), Kiel.

Fitzenberger, B., And A. Garloff (2004): "Descriptive Evidence on Labour Market Transitions and the Wage Structure for Germany," unpublished manuscript, Centre of European Economic Research (ZEW), Mannheim.

Fitzenberger, B., A. Garloff, and K. Kohn (2003): "Beschäftigung und Lohnstrukturen nach Qualifikationen und Altersgruppen: Eine empirische Analyse auf Basis der IAB-Beschäftigtenstichprobe," Mitteilungen aus der Arbeitsmarkt- und Berufsforschung, 36(4), 509-524.

Fitzenberger, B., And K. Kohn (2004): "Skill-Wage Premiums, Employment, and Cohort Effects in a Model of German Labor Demand," unpublished manuscript, University of Frankfurt.

Fitzenberger, B., And A. Spitz (2004): "Die Anatomie des Berufswechsels: Eine empirische Bestandsaufnahme auf Basis der BIBB/IAB-Daten 1998/1999," Discussion Paper No. 04-05, Centre for European Economic Research (ZEW), Mannheim.

Franz, W. (2003): Arbeitsmarktökonomik. Berlin et al.: Springer-Verlag, fifth, completely revised edn. 
Garloff, A. (2003): "Lohndispersion und Arbeitslosigkeit: Neuere Ansätze in der Suchtheorie," Discussion Paper No. 03-60, Centre of European Economic Research (ZEW), Mannheim.

Gruetter, M., and R. Lalive (2004): "The Importance of Firms in Wage Determination," unpublished manuscript: University of Zurich.

Hamermesh, D. S. (1993): Labor Demand. Princeton: Princeton University Press.

Krueger, A. B., And J.-S. Pischke (1998): "Observations and Conjectures on the U.S. Employment Miracle," in Third Public GAAC Symposium: Labor Markets in the USA and Germany, pp. 99-126. Bonn: German-American Academic Council.

Krugman, P. (1994): "Past and Prospective Causes of High Unemployment," in Reducing Unemployment: Current Issues and Policy Options, Proceedings of a Symposium in Jackson Hole, ed. by Federal Reserve Bank of Kansas City, pp. 66-81. WY, Kansas City, MO.

Kuckulenz, A., And T. Zwick (2003): "The Impact of Training on Earnings Differences Between Participant Groups and Training Forms," Discussion Paper No. 03-57, Centre for European Economic Research (ZEW), Mannheim.

Lauer, C. (2003): "Education and Unemployment: A French-German Comparison," Discussion Paper No. 03-34, Centre for European Economic Research (ZEW), Mannheim.

Moen, E. R. (1999): "Education, Ranking and Competition for Jobs," Journal of Labor Economics, 17(4), 694-723.

Mortensen, D. T., and G. R. Neumann (1988): "Estimating Structural Models of Unemployment and Job Duration," in Dynamic Econometric Modeling. Proceedings of the Third International Symposium in Economic Theory and Econometrics, ed. by W. A. Barnett, E. R. Berndt, and H. White, chap. 15, pp. 335-355. Cambridge et al.: Cambridge University Press.

Mortensen, D. T., and C. A. Pissarides (1999): "New Developments in Models of Search in the Labor Market," in Handbook of Labor Economics, ed. by O. Ashenfelter, and D. Card, vol. 3B, chap. 39, pp. 2567-2627. Amsterdam et al.: Elsevier.

Pfeiffer, F. (2003): Lohnrigiditäten in gemischten Lohnbildungssystemen. BadenBaden: Nomos.

Rosholm, M., and M. Svarer (2004): "Endogenous Wage Dispersion in a SearchMatching Model," Labour Economics, 11(5), 623-645.

VAn den Berg, G. J., And G. Ridder (1993): "Estimating an Equilibrium Search Model from Wage Data.," in Panel Data and Labour Market Dynamics, ed. by H. Bunzel, P. Jensen, and N. Westgard-Nielsen, vol. 222 of Contributions to Economic Analysis, pp. 43-55. Amsterdam et al.: Elsevier.

66(5), 1183-1221. 
Wilke, R. A. (2004): "New Estimates of the Duration and Risk of Unemployment for West-Germany," Discussion paper No. 04-26, Centre for European Economic Research (ZEW), Mannheim.

Wooldridge, J. M. (2002): Econometric Analysis of Cross Section and Panel Data. Cambridge/ London: MIT Press. 